\title{
Examination Anxiety as Correlate of Junior High School Pupils Academic Performance in the Effutu Municipality of Ghana
}

\author{
Joseph Bentil \\ Department of Basic Education, \\ University of Education, Winneba, GHANA
}

\begin{abstract}
This study investigated the relationship between examination anxiety and pupils' academic performance in Junior High Schools in Effutu Municipality in the Central Region of Ghana. Grounded in Smith and Ellsworth (1987) transactional model of testrelated emotions, this study adopted the cross-sectional descriptive survey design with quantitative approach where seven-hundred and forty one (741) Junior High School pupils were sampled through the multi-stage sampling technique. Closed-ended questionnaire was used to collect quantifiable data. After satisfying validity and reliability requirements, the instrument was self-administered to the participants and the data was analyzed using descriptive statistics (frequency, percentages, mean, standard deviation) and inferential statistics such as t-test, ANOVA, and Pearson Product Moment Correlation. The findings of the study revealed that generally there was high examination anxiety among the Junior High School pupils. Besides, the results showed that there was a strong and statistically significant inverse relationship between examination anxiety and pupils overall academic performance. The study further disclosed that the level of pupils and age of the pupils did not significantly affect examination anxiety. Furthermore, it was revealed that sex and type of school attended significantly influenced examination anxiety. Therefore, it is recommended among others that, the Effutu Municipal Education Directorate should as a matter of urgency design and implement programmes to reduce the high anxiety levels among pupils so as to enhance academic performance. In this direction, attention should be directed to sex and type of school attended since these two variables significantly predicted examination anxiety.
\end{abstract}

Keywords: Examination anxiety, academic performance, and Junior High School pupils

\section{INTRODUCTION}

Globally, formal education has been touted as the driver of socio-economic advancement of all societies. This claim was supported by Omoniyi and Oluniyi (2012) who argued that quality education is an instrument for fostering the worth and development of individual and for general development of the society. In essence, the development of a country is likely to repress if concerted efforts are not made towards the provision of quality education to the citizenry. Therefore, countries especially the developing ones, are preoccupied with the pursuit to improve the quality of education and the achievement of students since it correlates largely with the quality of education being offered (Kgosikebatho, 2013; Onyesom \& Ashibogwu, 2013). Extant literature fingers students' academic performance as a vital antecedent of quality education. Deductively, students of good academic standing are perceived to have demonstrated a grasp of relevant concepts, knowledge, skills, and attitudes to take leadership positions and man the various sectors of the economy. Conversely, poor academic performance of pupils is evident of lack of necessary capacities for socio-economic progress and personal fulfillment. 
Meanwhile, in educational institutions, it has been established that tests are not only unavoidable, but they are in principle the fundamental tool employed in measuring students academic achievements. This evaluative situation often comes with several criticisms with some scholars questioning the very essence of education. According to Ackummey, AttaBoison, Hama, Kankam, Ohene-Darko, Owusu-Mensah and Quist (2001), the goal of education is to address the cognitive, affective, and psychomotor competencies of learners so as to develop their total personality. It could be deduced from these perspectives that tests or examinations are necessary but inadequate means for measuring educational effectiveness, and that other assessment strategies are required to complement it. Contrarily, other practitioners assume that examination is essential in measuring educational attainment of students. Segool, Goforth, Carlson, Von der Embse and Barterian (2013) lend credence to this assertion when they noted that educational systems test students from a young age to evaluate their performance. Besides, Rana and Mahmood (2010) observed that in this test conscious age, the lives of many are not only greatly influenced but are also determined by their test performance. Numerous studies have established that examination outcomes are more accurate and precise in assessing student academic abilities (Yousefi, Talib, Mansor, Juhari \& Redzuan, 2010).

In Ghana, selection and placement of students into higher education and programmes are all based on testing or examinations. With the Computerized School Selection and Placement System (CSSPS) which is a competitive selection into Senior High Schools and programmes is based on students' performance in the Basic Education Certificate Examination (BECE). Similarly, academic excellence, qualifications and high performance achievement have been regarded as the yardstick for recruitment, placement and advancement in both public and private sector organizations. More importantly, these parameters are highly adopted in the selection of candidates for admission into tertiary institutions and colleges. Due to this, high premium is placed on academic performance, as individuals do everything possible to obtain excellent results. This no doubt places students at varying levels of anxiety and tension in the process. Due to the importance attached to tests and their grades as predictive factors, anxiety has been raised in the minds of many students.

Besides, educationists and academicians such as Deb, Chatterjee and Walsh (2010) have unveiled that the uncertainties, qualms and fears of the results of examinations and their resultant consequences make students susceptible to considerable anxiety. This assertion is further strengthened by Cassady (2010) where it was estimated that between $25 \%$ and $40 \%$ of students experience examination anxiety which significantly interfere with their academic performance. Bonaccio and Reeve (2010) also stressed that some students have no problem with tests, but many are impacted by the anxiety a testing scenario presents. In essence, examination anxiety is a major determinant of success in examinations, and, therefore, requires a systematic investigation. Asadullapoor, Fati and Gharaee (2010, p. 8) conceptualized examination anxiety as "The subjective feeling of tension, apprehension, nervousness, and worry associated with an arousal of the automatic nervous system." Chapell, Blanding, Takahaski, Silverman, Newman, Gubi and Mccann (2005) explicated that examination anxiety is a multi-dimensional phenomenon that encompasses uneasiness, emotionality, and behavioural response to being preoccupied by the possible negative outcome of academic scores. These definition suggests that examination anxiety is the feeling of apprehension which learners portray due to their perception of undesirable outcome of an impending examination. It is inferred from this definition that it is not examination per se that elicits anxiety, but rather the fear of its negative outcome. 
The debilitating consequences of test anxiety include attrition amongst students, students being usually tensed, apprehensiveness, nervousness and emotionally aroused which ultimately results in poor academic performance. Other practitioners have underscored the importance of appreciable level of anxiety (Bonaccio \& Reeve, 2010; Duty, Christian, Ioftus \& Zappi, 2016). High test anxiety is also connected with low self-confidence, poor reading, failing grades, disruptive classroom behaviour, negative attitudes toward school, and unpleasant feelings of nervousness and dread that stem from an intense fear of failure (Barrows, Dunn \& Lloyd, 2013; Saeidi \& Khaliliaqdam (2013). While the above studies recount on the devastating outcomes of test anxiety, Dordinejad, Hakimi, Ashouri, Dehghani, Zeinali, and Daghighi (2011) posited that a usual level of test anxiety in students not only motivates them to work hard but also provides them with some positive upshots. Likewise, Salend (2011) noticed that appropriate levels of anxiety can enhance students' memory, attention, motivation, and lead to improved test performance. Implicitly, when anxiety points exceed appropriate levels, it can have devastating effects on academic performance.

Consequently, available literature has disclosed that research on test anxiety and its impact on students' academic performance have received considerable attention in recent decades and results are inconclusive. For instance, previous studies (Barrows et al., 2013; Steinmayr, Crede \& Wirthwein, 2016; \& Duty, et al., 2016) have all discovered that test anxiety negatively affects students' academic performance. These findings suggest that examination anxiety negatively correlated with academic performance among students. However, findings from Afolayan, Donald, Onasoga, Babafemi and Juan (2013) and Cheraghian, Fereidooni-Moghadam, BarazPardjani, \& Bavarsad (2008) revealed that there was no significant relationship between test anxiety and students' academic performance. It is inferred from these studies that the lack of consensus on the effect of anxiety on academic performance is still not resolved, thus calls for further study.

Literature has indicated that examination anxiety exists on a continuum: low, moderate, severe and as such, several studies have reported various levels of examination anxiety among students. On their part, Ferdous (2012) and Guress, Kaya, Dogar, Gunes, and Hasan (2010) discovered that students showed high levels of examination anxiety. It was also revealed that lower grade students exhibited higher level of test anxiety than higher grade students. Similarly, Dordinejad, Hakimi, Ashouri, Dehghani, Zeinali, and Daghighi (2011) established that there is high level of anxiety among students. In another study, however, Driscoll et al., (2009) concluded that students had moderate level of examination anxiety. Cherry (2012) discovered that students who exhibit moderate levels of examination anxiety are able to perform relatively well on examinations. These conflicting findings call for further studies to shed more lights on the level of examination anxiety in specific settings for appropriate actions to be taken.

The influence of demographic variables (sex, age, level \& type of school) of pupils and how these variables influence the anxiety levels of pupils have caught considerable attention of researchers in recent times. Putwain (2007), for instance, observed that from elementary school across cultures, females typically reported higher levels of examination anxiety than males. The findings of Zaheri, Shahoei and Zaheri (2012) supported the earlier result that examination anxiety has tremendously influenced by gender where males demonstrated lower levels of anxiety than females. However, the outcome of this study contradicts with other studies (McDonald, 2001; Fiore, 2003) where it was discovered that there was no difference in test anxiety due to sex. From these results, it is likely to suggest that genetically, males have an inbred capacity to cope with examination anxiety than their female counterparts. Thus, 
regardless of the conditions under which an examination is taken, females are at risk of the repercussions of examinations anxiety than the males.

The age of students featured as one of the critical factors that influence examination anxiety of students. For instance, Healy (2009) discovered that age affected the anxiety level of the students, and that anxiety decreased when students get older. This suggests that examination anxiety was higher among younger students as compared with those who are relatively older. This finding was contested in other studies where it was reported that age showed no significant relationship with examination anxiety (Ebrahimi \& Khoshsima, 2014). With reference to this finding, it is maintained that age does not play a significant role in determining learners' examination anxiety. This contradiction requires further investigations in different contexts and cultures.

On grade levels, previous studies such as Fulya (2008) disclosed that grade level did not account for differences in test anxiety among pupils. However, researchers such as Ferdous (2012) unveiled that higher test anxiety exist among lower grade students than higher grade students. Additionally, Sansgiry and Sail's (2006) study also revealed that students of higher grades recorded higher test anxiety than lower grade students. In conclusion, the influence of grade level on test anxiety has produced divergent results, hence, empirical evidence is required in specific settings. On whether the type of school attended (public/private) have any significant relationship with test anxiety levels of students, Bhatta, Subba and Bhandary (2018) disclosed that students of private schools were having significantly higher test anxiety compared to those studying in public schools. Result was contrary to the findings of Akanbi (2013) where students in public schools exhibited higher anxiety levels than their private school counterparts. The literature has also shown that researchers differed in their findings on the influence of these variables on students' examination anxiety levels. Hence, studies are required to explore these variables in other contexts like the Effutu Municipality.

In Ghana, academic performance of students has become a matter of concern to all education stakeholders in recent decades. The Ministry of Education (2017) has observed that Ghana has witnessed increased poor pupils performance in recent times. In the Effutu Municipality, academic attainment of pupils in Junior High Schools especially in the Basic Education Certificate Examinations (BECE) has not been encouraging as presented in Table 1.

The analysis of BECE results in Table 1 revealed that the average academic performance for the municipality from 2013 to 2018 was $54.2 \%$. In 2013, the municipality recorded $42.5 \%$ pass while the failure rate was $57.5 \%$.

Table 1: Academic Achievement of Pupils in Basic Education Certificate Examination (2013-2016)

\begin{tabular}{ccc}
\hline Year & Pass Rate (\%) & Failure Rate (\%) \\
\hline 2013 & 42.5 & 57.5 \\
2014 & 44.0 & 56.0 \\
2015 & 44.8 & 55.2 \\
2016 & 54.7 & 45.3 \\
2017 & 70.2 & 29.8 \\
2018 & 69.5 & 30.6 \\
\hline
\end{tabular}

Source: Effutu Municipal Examination Unit of Ghana Education Service (2013-2018)

Performance in 2014 increased with $44.0 \%$ of the pupils passed and $56.0 \%$ failed. There was a slight improvement in performance in 2015 over the previous year with $44.8 \%$ pass and $55.2 \%$ failure. The 2016 academic year noticed further improvement in performance with $54.7 \%$ pass 
and $45.3 \%$ failure. In 2017, the academic performance of pupils in the municipality improved with $70.2 \%$ pass and $29.8 \%$ failure. In 2018 , performance dropped where $69.5 \%$ of the pupils passed while $30.5 \%$ failed. These results have proven that in recent times, almost half of the pupils in the municipality were unable to pass and enter second cycle institutions.

Considering the point made by the Ministry of Education (2017) that one of the serious challenges of Ghana's educational system is pupils' performance, studies to investigate the determinants of pupils' academic performance is relevant. Meanwhile, research evidence exists to validate the fact that examination anxiety affects academic performance of students (Steinmayr, et al., 2016; \& Duty, et al., 2016). Consistently, this study hypothesizes that the poor pupils' academic performance could be attributed to the examination anxiety they experience during examinations. The researcher is inclined to believe that the existence of the examination anxiety among pupils in the municipality is likely to affect their academic performance albeit no evidence is available to support this claim. This study is therefore carried out to gather empirical proofs to shed more light on the link between examination anxiety and pupils' academic performance in the Effutu Municipality of Ghana.

The study was guided by the following research questions:

1. What is the level of examination anxiety among Junior High School pupils in the Effutu Municipality?

2. What is the relationship between examination anxiety and pupils academic performance in Junior High Schools in the Effutu Municipality?

\section{Hypotheses}

Ho1: There is no statistically significant difference between male and female Junior High School pupils and their level of examination anxiety in the Effutu Municipality.

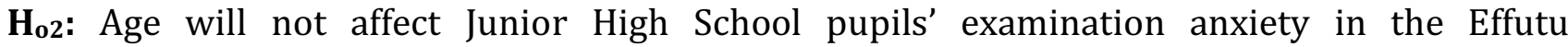
Municipality.

Ho3: Level of pupils (JHS 1, JHS 2 \& JHS 3) will not significantly influence their examination anxiety in the Effutu Municipality.

$\mathbf{H}_{\mathbf{0} 4}$ : Type of school attended by the pupils (public/private) will not significantly influence their examination anxiety in the Effutu Municipality.

It is envisage that the result of the study would not only help expand the borders and boundaries of knowledge in the field of examination anxiety and its influence on pupils' academic performance but would also assist school authorities to be aware of the level of examination anxiety among the pupils. This will help authorities to proffer strategies to enable pupils to cope and deal with their anxiety and boost their academic performance. Additionally, through this study, pupils will be made aware of the degree to which examination anxiety affects their performance, this will cause them to apply themselves to measures and strategies to manage their anxiety levels for improved academic performance.

\section{THEORETICAL FRAMEWORK}

Smith and Ellsworth (1987) transactional model of test-related emotions constitutes the theoretical framework of the study. This theory has been used expansively by researchers. In explaining the main thrust of the theory, researchers (Liebert \& Morris, 1967; Zeidner, 1998) have argued that test anxiety is triggered by two main factors; namely worry and emotionality. To these researchers, worry factor entails the cognitive components of test anxiety which results in the student having gloomy expectations, being absent-minded, self-criticism, and irrational outcomes which have been discovered to negatively correlate with academic performance. The emotionality factor relates to physiological attributes such as heart rate, 
feeling of sickness, sweating, tense muscles, etc. (Liebert \& Morris, 1967; Zeidner, 1998). Some scholars have offered other models in explaining test anxiety such as Skills-Deficit Model and the Cognitive-Attentional Model. However, researchers such as (Liebert \& Morris, 1967; Zeidner, 1998) maintained that these models have been proven to lack significant experimental evidence to influence academic achievement. For instance, in arguing for lack of significant experimental evidence on Skills-Deficit and the Cognitive-Attentional Models, these scholars theorized that although some high test-anxious individuals lack appropriate study skills which is the main thrust of Skills-Deficit Model, improving this skill alone does not trigger an increase in achievement or to a reduction in examination anxiety. Also, most high testanxious students study on average longer than their low test-anxious colleagues and have demonstrated equal performance when examined in a less evaluative circumstances. Hence, the use of the transactional model of test-related emotions has caught the attention of researchers over the previous decade in explaining examination anxiety amongst students (Deloatch, 2017). Therefore, the outcome of research based on this theory could be used in making inferences on other examination anxiety theories.

\section{METHODOLOGY}

This study adopted the cross-sectional descriptive survey design with quantitative approach. This design gathers information about the occurrence, distribution, and interrelations of variables within a population where data are usually gathered through self-reporting (Polit \& Beck, 2014) which is well positioned by way of the purpose of the study. In this study, the population comprised all Junior High School pupils in basic schools in the Effutu Municipality totalling 4,546 and was made up of 1,741 girls and 1,805 boys. Through the proportionate stratified random sampling, a sample of 746 Junior High pupils consistent with Wiersema's (2009) proposal of $30 \%$ of the population as being representative in surveys were selected and participated in the study. The population was put into two strata by sex, and a proportionate sampling procedure was followed to select each stratum so that the sample resembles the population. The male population was $54 \%$ and the remaining $46 \%$ was for the females. The main principle of the proportionate stratified sampling is that each member of the population has equal chance of being selected to be in the sample, and that the sample replicates the population (Cohen, Manion \& Morrison, 2011).

The instruments used for data collection included a structured questionnaire and a checklist. The structured questionnaire dubbed Cognitive Test Anxiety Scale (CTAS) which was adopted from Cassady and Johnson (2002). It contained twenty seven (27) items measured on a 4-point Likert scale questionnaire such that $1=$ Not at all typical of me, $2=$ only somewhat typical of me, $3=$ Quite typical of me, and 4= Very typical of me which required the pupils to rate every option to describe their anxiety level. The checklist was used to collect end of term examination scores in English Language, Integrated Science, Mathematics, and Social Studies for 2018/2019 academic year. These subjects were considered because they are core subjects that all pupils study and are crucial in determining pupils' grades at the BECE. The examination was conducted by the Effutu Municipal Education Directorate which was considered to be standardized. Hence, comparison could be made based on the results of the examination within the municipality.

In this study, reliability of the questionnaire was determined through internal consistency of items where Crobach's alpha coefficients were computed and results revealed coefficient of 0.85 for Cognitive Test Anxiety Scale (CTAS) which is deemed reliable based on the suggestion of Bryman and Bell (2012) that Cronbach alpha coefficients of at least 0.70 is indicative of reliability. Validation of the instruments was checked as the researcher sought the views of some faculty members and a Professor where typographical mistakes, ambiguities, 
grammatical errors, as well as the expert advice were all incorporated in putting the instrument to shape before the actual data collection.

Prior to data analysis, the data was cleaned and poorly answered questionnaires were eliminated. The data were entered into the version 22 of the Statistical Product for Service Solutions (SPSS), and explored to identify missing data and outliers. To ensure that there was uniformity regarding the scale of measurement in the data for both the independent (examination anxiety) and dependent (academic performance) variables for inferential analysis, the pupil's test scores hitherto measured in percentages, were converted into a 4point Likert scale to correspond with the questionnaire value. For example, $60 \%$ in the examination was converted, thus: $60 / 100 \times 4=2$. Descriptive statistics such as frequency, percentage, mean, and standard deviation and inferential statistics such as the independent samples t-test, and one-way between groups analysis of variance (ANOVA) and Pearson Moment Correlation were used for analysis after the assumptions underlying the use of inferential statistics have been checked and satisfied. After meeting the ethical requirements of anonymity, confidentiality, and informed consent as criteria of conducting research, the researcher self-administered the instruments to the participants.

\section{Demographic Characteristics of Respondents}

\section{ANALYSIS OF RESULTS AND DISCUSSION}

The demographic characteristics of the pupils were examined, and the results are shown in Table 2.

Table 2: Demographic Characteristics of Respondents

\begin{tabular}{llcc}
\hline Variables & & Frequency & Percentage \\
\hline Sex & Male & 369 & 49.8 \\
& Female & 372 & 50.2 \\
Age & Total & $\mathbf{7 4 1}$ & $\mathbf{1 0 0 . 0}$ \\
& Less than 13 & 101 & 13.6 \\
& $14-16$ & 402 & 54.3 \\
Level & 17 and Above & 238 & 32.1 \\
& Total & $\mathbf{7 4 1}$ & $\mathbf{1 0 0 . 0}$ \\
& JHS 1 & 321 & 43.3 \\
& JHS 2 & 146 & 19.7 \\
Type of School & JHS 3 & 274 & 37.0 \\
& Total & $\mathbf{7 4 1}$ & $\mathbf{1 0 0 . 0}$ \\
& Public & 535 & 72.2 \\
& Private & 206 & 27.8 \\
\hline
\end{tabular}

Source: Fieldwork, 2019

It could be seen from the data in Table 2 that more females $(n=372,50.2 \%)$ than males $(n=369$, 49.8\%) were involved in the study. The information also disclosed that majority of the respondents were between 14-16 years $(n=402,54.3 \%)$ as compared to those who were 17 years and above $(n=238,32.1 \%)$, and less than $13(n=101,13.6 \%)$ years. The composition of the respondents based on their level of study showed that the proportion of those who were in JHS $1(n=321,43.3 \%)$ were more than JHS $3(n=274,37.0 \%)$, and JHS $2(n=146,19.7 \%)$ respectively. The distribution of the respondents by type of school attended revealed that those in public schools $(n=535,72.2 \%)$ were more than those in private schools $(n=206$, $27.8 \%$ ) respectively. The demographic compositions of the respondents were vital to the study in two folds. Firstly, they confirmed that data were collected from a sample with varied backgrounds which suggested that the data were rich and representative of the population. 
Secondly, the demographic characteristics were used as the basis of comparison of the respondents on the study variables.

\section{Research Question 1 - What is the level of examination anxiety among Junior High} School students in the Effutu Municipality?

The aim of this research question was to determine the level of examination anxiety as experienced by Junior High School pupils in the Effutu Municipality. In this research question, the instrument used in determining the level of examination anxiety was adopted from Cassady and Johnson (2002) which contained twenty seven (27) items which were required to rate every option to describe their anxiety level and have proposed a mean range in determine the level of anxiety. In this study, the level of examination anxiety was determined based on the suggestion of Cassady and Johnson (2002) as shown in Table 3.

Table 3: Interpretation of Levels of Examination Anxiety

\begin{tabular}{cll}
\hline Scale & Range of Mean Scores & Interpretation \\
\hline 1 & $27-61$ & Low Anxiety \\
2 & $62-71$ & Moderate Anxiety \\
3 & $\leq 72$ & High Anxiety \\
\hline \multicolumn{3}{c}{ Source: Cassady and Johnson (2002) }
\end{tabular}

The results on the level of examination anxiety as experienced by the Junior High School students are presented in Table 4.

Table 4: Levels of Examination Anxiety

\begin{tabular}{lcc}
\hline & Mean & Std. Deviation \\
\hline Examination Anxiety & 72.15 & 5.93 \\
\hline
\end{tabular}

Source: Fieldwork, 2019

Comparing the results in Table 4 to the criteria set by Cassady and Johnson (2002) as contained in Table 3, it could be observed that generally the level of examination anxiety $(M=72.15, S D=5.93)$, among Junior High School pupils in the Effutu Municipality is high. The findings of this study is consistent with previous studies (Ferdous, 2012; Dordinejad et al., 2011; Guress, 2010) where their findings revealed high examination anxiety amongst students and examination triggers the anxiety level of the learners in all jurisdictions. However, the result of this study contradicts that of Cherry (2012) which reported moderate levels of examination anxiety.

\section{Research Question Two - What is the relationship between examination anxiety and students academic performance in Junior High Schools in the Effutu Municipality?}

This research question sought to investigate the link between examination anxiety and pupils academic performance. To provide answers to this research question, the Pearson Moment Correlation was used where the coefficients for the variables were computed, and the results are presented in Table 5. The interpretation of the strength of the relationship was based on the recommendation by Kothari's (2004) which indicated that if the correlation coefficient is less than 0.3, then the relationship is weak; the relationship is moderate if the correlation coefficient is greater than 0.3 but less than 0.5 ; and the relationship is strong if the correlation coefficient is 0.5 or greater.

In comparing the results in Table 5 to the recommendation proffered by Kothari (2004), it is observed that generally, there was a strong and statistically significant inverse relationship 
between examination anxiety and pupils overall academic performance $(\mathrm{r}=-0.76, \mathrm{p}<0.05,2$ tailed). This finding implied that the higher the level of examination anxiety, the lower the academic performance, and the lower the examination anxiety, the higher the academic performance.

Table 5: Pearson Correlation Matrix for Examination Anxiety and Pupils Academic Performance

\begin{tabular}{|c|c|c|c|c|c|c|c|}
\hline & & 1 & 2 & 3 & 4 & 5 & 6 \\
\hline & Mean & 3.45 & 3.51 & 3.18 & 3.10 & 3.19 & 3.22 \\
\hline & Standard Deviation & 0.64 & 0.65 & 0.94 & 0.83 & 0.92 & 0.57 \\
\hline 1. & English Language & 1 & & & & & \\
\hline 2 & Integrated Science & $\begin{array}{c}0.36^{*} \\
(0.00)\end{array}$ & 1 & & & & \\
\hline 3 & Mathematics & $\begin{array}{l}0.35^{*} \\
(0.00)\end{array}$ & $\begin{array}{l}0.26^{*} \\
(0.00)\end{array}$ & 1 & & & \\
\hline 4 & Social Studies & $\begin{array}{l}0.46^{*} \\
(0.00)\end{array}$ & $\begin{array}{l}0.45^{*} \\
(0.00)\end{array}$ & $\begin{array}{c}0.29 * \\
(0.00)\end{array}$ & 1 & & \\
\hline 5 & $\begin{array}{l}\text { Overall Academic } \\
\text { Performance }\end{array}$ & $\begin{array}{c}0.75^{*} \\
(0.00)\end{array}$ & $\begin{array}{l}0.72^{*} \\
(0.00)\end{array}$ & $\begin{array}{l}0.66^{*} \\
(0.00)\end{array}$ & $\begin{array}{c}0.75^{*} \\
(0.00)\end{array}$ & 1 & \\
\hline 6 & Examination Anxiety & $\begin{array}{c}0.41^{*} \\
(0.00)\end{array}$ & $\begin{array}{l}-0.89^{*} \\
(0.00)\end{array}$ & $\begin{array}{l}0.81^{*} \\
(0.00)\end{array}$ & $\begin{array}{c}0.80^{*} \\
(0.00)\end{array}$ & $\begin{array}{l}-0.76^{*} \\
(0.00)\end{array}$ & 1 \\
\hline
\end{tabular}

$\mathrm{N}=741{ }^{*}$ Correlation is significant at $\mathrm{p}<0.05$ (2-tailed) NB: $\mathrm{p}$-values are in brackets Source: Fieldwork, 2019

It was also established that there was a strong and statistically significant positive relationship between examination anxiety and academic performance in social studies $(r=0.80, p<0.05,2$ tailed). Furthermore, the study showed that there was a strong and statistically significant positive relationship between examination anxiety and academic performance in Mathematics $(\mathrm{r}=0.81, \mathrm{p}<0.05,2$-tailed). There was an inverse statistically significant relationship between examination anxiety and academic performance in Integrated Science $(r=-0.89, p<0.05,2$ tailed). Finally, the relationship between examination anxiety and performance in English Language $(\mathrm{r}=0.41, \mathrm{p}<0.05,2$-tailed) was moderately statistically significant. The study has produced empirical evidence to conclude that there was a strong and statistically inverse relationship between examination anxiety and pupils' academic performance. The findings of this study resonate with previous studies (Barrows et al., 2013; Steinmayr, et al., 2016; \& Duty, et al., 2016) which discovered that test anxiety negatively affects students' academic performance. This finding departs from those of Afolayan et al., (2013) and Cheraghian (2008) findings which revealed that there was no significant relationship between test anxiety and students' academic performance.

\section{Hypothesis One}

Ho1: There is no statistically significant difference between male and female Junior High School pupils and their level of examination anxiety.

To provide answers to this hypothesis, the independent samples t-test was used where the mean and standard deviation of male and female pupils on their examination anxiety were investigated to see if statistically significant differences exist, and the results are presented in Table 6. 
Table 6: T-test Results for Pupils Gender and Level of Examination Anxiety

\begin{tabular}{lcccccc}
\hline & Sex & Mean & $\begin{array}{c}\text { Std. } \\
\text { Deviation }\end{array}$ & t & df & $\begin{array}{c}\text { Sig. (2- } \\
\text { tailed) }\end{array}$ \\
\hline Examination Anxiety & Male & 72.58 & 6.25 & -1.878 & 739 & 0.061 \\
& Female & 73.51 & 6.89 & & & \\
\hline
\end{tabular}

Source: Fieldwork, 2019

It could be observed from Table 6 that female pupils experienced higher examination anxiety $(M=73.51, S D=6.89)$ than their male counterparts $(M=72.58, S D=6.25)$. However, the t-test results have shown that there was a statistically significant difference in the examination anxiety between male and female pupils [t $(739)=-1.878, p=0.061,2$-tailed] at 0.05 alpha level. Consequently, the null hypothesis that there is no statistically significant difference between male and female Junior High School pupils and their level of examination anxiety was not supported whilst the alternative hypothesis that there is a statistically significant difference between male and female Junior High School pupils and their level of examination anxiety was supported. Based on these findings, there is enough evidence to conclude that gender is a critical factor that influenced examination anxiety of pupils in Junior High Schools in Effutu Municipality. This finding is congruent with those of Putwain (2007) and Zaheri (2012) where it was revealed that females typically reported higher levels of examination anxiety than males. However, the outcome of this study contradicts with other studies (McDonald, 2001; Fiore, 2003) where it was discovered that there was no difference in test anxiety due to sex.

\section{Hypothesis 2}

Ho2: Age will not affect Junior High School pupils' examination anxiety in the Effutu Municipality.

The one-way between groups ANOVA was used to provide answers to this hypothesis, and the results are shown in Table 7.

Table 7: ANOVA Results for Pupils Age and Examination Anxiety

\begin{tabular}{|c|c|c|c|c|c|c|c|c|}
\hline Age in Years & $\mathbf{N}$ & Mean & $\begin{array}{c}\text { Std. } \\
\text { Deviation }\end{array}$ & $\begin{array}{c}\text { Sum of } \\
\text { Squares }\end{array}$ & df & $\begin{array}{c}\text { Mean } \\
\text { Square }\end{array}$ & $\mathbf{F}$ & P-Value \\
\hline Less than 13 & 101 & 2.73 & 0.58 & 0.814 & 2 & 0.407 & 1.254 & 0.286 \\
\hline $14-16$ & 402 & 2.63 & 0.55 & 239.446 & 738 & 0.324 & & \\
\hline 17 and Above & 238 & 2.65 & 0.60 & 240.260 & 740 & & & \\
\hline Total & 741 & 2.65 & 0.57 & & & & & \\
\hline
\end{tabular}

Source: Fieldwork, 2019

The ANOVA results in Table 7 revealed that there were no statistically significant differences in the examination anxiety amongst Junior High School pupils $[F(2,738)=1.254, p=0.286]$ at 0.05 due to age. These results confirmed that age is not a determinant of Examination anxiety among Junior High School pupils in the Effutu Municipality. As a result, the null hypothesis that age will not affect Junior High School pupils' examination anxiety in the Effutu Municipality was accepted while the alternate hypothesis was rejected. Hence, Healy's (2009) revelation that age affected the anxiety level of the students did not reflect in this study and that anxiety decreased when students get older. This suggests that examination anxiety was higher among younger students as compared with those who are relatively older. Nevertheless, the results corroborated that of Ebrahimi and Khoshsima (2014) where it was reported that age showed no significant relationship with examination anxiety. 


\section{Hypothesis 3}

$\mathbf{H}_{\mathbf{0} 3}$ : Level of pupils (JHS 1, JHS 2 \& JHS 3) will not significantly influence their examination anxiety in the Effutu Municipality.

To answer this hypothesis, one-way between groups ANOVA test was conducted, and the results are presented in Table 8.

Table 8: ANOVA Results for Level of Pupils and Examination Anxiety

\begin{tabular}{ccccccccc}
\hline Level & N & Mean & $\begin{array}{c}\text { Std. } \\
\text { Deviation }\end{array}$ & $\begin{array}{c}\text { Sum of } \\
\text { Squares }\end{array}$ & df & $\begin{array}{c}\text { Mean } \\
\text { Square }\end{array}$ & F & Sig. \\
\hline JHS 1 & 321 & 2.70 & 0.61 & 1.559 & 2 & 0.780 & 2.411 & 0.090 \\
JHS 2 & 146 & 2.58 & 0.48 & 238.700 & 738 & 0.323 & & \\
JHS 3 & 274 & 2.64 & 0.56 & 240.260 & 740 & & & \\
Total & 741 & 2.65 & 0.57 & & & & & \\
\hline
\end{tabular}

Source: Fieldwork, 2019

As indicated in Table 8, the ANOVA results showed that there were no statistically significant differences in examination anxiety of the pupils $[\mathrm{F}(2,738)=2.411, \mathrm{p}=0.090]$ at 0.05 based on their level. As a result, the study concluded that the level of the pupils in the Effutu Municipality did not affect their examination anxiety. Accordingly, the null hypothesis that level of pupils (JHS 1, JHS 2 \& JHS 3) will not significantly influence their examination anxiety in the Effutu Municipality is supported while the alternate hypothesis was not supported. The finding of the study is consistent with that of Fulya, (2008) which showed that grade level did not account differences in test anxiety among students. Contrarily, previous researchers (Mansor et al., 2009; Ferdous, 2012) unveiled that higher test anxiety exist among lower grade students than higher grade students.

\section{Hypothesis 4}

$\mathbf{H}_{\mathbf{0}}$ : Type of school attended by the students (public/private) will not significantly influence their examination anxiety in the Effutu Municipality.

To answer this hypothesis, the independent samples t-test was employed, and the results are presented in Table 9.

Table 9: T-test Results for Type of School Attended and Level of Examination Anxiety

\begin{tabular}{lcccccc}
\hline & & \multicolumn{5}{c}{ Std. } \\
& Type of School & Mean & Deviation & t & df & Sig. (2-tailed) \\
\hline Examination Anxiety & Public & 73.07 & 5.37 & 2.240 & 739 & 0.025 \\
& Private & 72.65 & 6.71 & & & \\
\hline
\end{tabular}

Source: Fieldwork, 2019

The t-test results in Table 9 revealed that there was a statistically significant difference in the mean scores for public $(M=73.07, S D=5.37)$ and private $(M=72.65, S D=6.71)$ schools on their examination anxiety [t (739) $=2.240, \mathrm{p}=0.025,2$-tailed] at 0.05 alpha level. Therefore, the results provided evidence that the type of school attended did account for differences in their examination anxiety. Based on these results, the null hypothesis that there is no statistically significant difference between public and private Junior High School pupils and their level of examination anxiety was rejected whilst the alternative hypothesis was accepted. This resonates with Akanbi's (2013) study where students in public schools exhibited higher anxiety levels than their private school counterparts. However, the result of this study 
digresses from Bhatta et al.'s, (2018) revelation that students of private schools were having significantly higher test anxiety compared to those studying in public schools.

\section{CONCLUSIONS AND RECOMMENDATIONS}

The study set out on the conviction that examination anxiety is a common occurrence amongst students in all educational institutions. Accordingly, literature has shown that examination anxiety is one of the major determinants of academic performance and will eventually ensue among students. Even though some scholars contend that some level of anxiety is necessary for good academic performance, there is enough proof to conclude that extreme level of anxiety shrinks academic performance of students at all levels. This is confirmed in this study where there was a negative relationship between examination anxiety and pupils' academic performance. Therefore, education stakeholders are expected to direct their resources and efforts towards minimizing the level of examination anxiety if they desire to enhance academic performance among the pupils. In this direction, the Municipality Guidance and Counseling Coordinator should collaborate with school guidance and counseling coordinators to plan and execute academic programmes to tackle the challenge of high examination anxiety among the pupils so as to boost their academic performance. It is worth noting that demographic factors like gender, and type of school attended were crucial demographic variables that predicted the test anxiety levels of students in the study area. Specifically, females and public basic schools pupils should be targeted since they experience higher anxiety than their counterparts, and therefore, are at risk. Therefore, stakeholders should pay attention to these factors in planning for academic programmes they wish to execute in reducing examination anxiety levels.

\section{References}

Ackummey, M A., Atta-Boison, G., Hama, J., Kankam, G., Ohene-Darko, C., Owusu-Mensah, F. \& Quist, F. (2001). Education and Culture. Accra, Ghana: Institute for Educational Development and Extension.

Afolayan, J. A., Donald, B., Onasoga, O., Babafemi, A., \& Juan, A. (2013). Relationship between anxiety and academic performance of nursing students. Niger Delta University, Bayelsa State, Nigeria. Advances in Applied Science Research, 4(5), 25-33.

Akanbi, S.T. (2013). Comparisons of test anxiety level of Senior Secondary School students across gender, Year of Study, School type and parental educational background. IFE Psychologia, 21(1), 40-54

Asadullapoor, A., Fati, L., \& Gharaee, B. (2010). Metacognitive anxiety and the immediate and delayed judgment of learning. Journal psychiat clinic psychol. 16(4), 412-19.

Barrows J., Dunn S., \& Lloyd C. A. (2013). Anxiety, self-efficacy, and college exam grade. Universal Journal of Education Research, 1, 204-208.

Bhatta, K. R., Subba, S. \& Bhandary, S. (2018). Test anxiety: Prevalence and correlates. International Journal of Current Research and Academic Review, 6(8), 75-82.

Bonaccio, S., \& Reeve, C. (2010). The nature and relative importance of students' perceptions of the sources of test anxiety. Learning and Individual Differences, 20(6), 617-625.

Bryman, A. \& Bell, E. (2012). Business Research Methods (3 ${ }^{\text {rd }}$ ed.). New York: Oxford.

Cassady, J. C. (2010). Test anxiety: Contemporary theories and implications for learning. New York, NY: Peter Lang.

Cassady, J.C., \& Johnson, R. E. (2002). Cognitive test anxiety and academic performance. Contemporary Educational Psychology, 27, 270-295.

Chapell, M. S., Blanding, Z. B., Takahashi, M., Silverstein, M. E., Newman, B., Gubi, A., \& Mccann, N. (2005). Test anxiety and academic performance in undergraduate and graduate students. Journal of Educational Psychology, 97 (2), 268-274.

Cheraghian, B., Fereidooni-Moghadam, M., Baraz-Pardjani, S. H., \& Bavarsad, N. (2008). Test Anxiety and its Relationship with Academic Performance among Nursing Students. Journal of Knowledge, and Health, 3(3), 25-29.

Cherry, K. (2012). Causes of test anxiety http://www.psychology.about.com/od/mentalhealth/a/test-anxietycauses.htm - Retrieved 24th April, 2018. 
Cohen, L., Manion, L. \& Morrisson, K. (2011). Research methods in education ( $7^{\text {th }}$ ed.). London: Routledge.

Deb, S., Chatterjee, P., \& Walsh, K. (2010). Anxiety among high school students in India: Comparisons across gender, school type, social strata and perceptions of quality time with parents. Australian Journal of Educational and Developmental Psychology, 10, 18-31.

Deloatch, R. T. (2017). Investigating test anxiety and the effects of supportive messages. Doctor of Philosophy Thesis, University of Illinois, United State of America.

Dordinejad, F., Hakimi, H., Ashouri, M., Dehghani, M., Zeinali, Z., Daghighi, M. (2011). On the relationship between test anxiety and academic performance. Procedia Soc Behav Sci. 15, 3774-3778.

Driscoll, R., Evans, G., Ramsey, G., \& Wheeler, S. (2009). High test anxiety among nursing students. Education Resources Information Center, 14 (4), 350-356.

Duty, S. M., Christian, L., Loftus, J., \& Zappi, V. (2016). Is cognitive test-taking anxiety associated with academic performance of nursing students. Nurse Educator, 41(2), 70-74.

Ebrahimi, M., \& Khoshsima, H. (2014). On the association(s) between test anxiety and emotional intelligence, considering demographic information: A case of Iranian EFL university students. International Journal on Studies in English Language and Literature (IJSELL), 2 (7), 147-157.

Ferdous, F. (2012). A case study of first-year non-English undergraduate students' English learning anxiety in Bangladesh. Journal of Education and Practice, 3(9), 1-11.

Fiore, A. M. (2003). Gender differences in test anxiety. A partial MA thesis, College of Human Resources and Education, West Virginia University.

Fulya, Y. S. (2008). "Mathematics anxiety among $4^{\text {th }}$ and $5^{\text {th }}$ grade Turkish elementary school students," International Electronic Journal of Mathematics Education, 3(3), 28-38.

Guress, A. Kaya, O. Dogar, C. Gunes, K. Hasan, Yolcu, H. (2010). Measurement of secondary school students' testanxiety levels and investigation of their causes. J. Social and Behavioral Sci., 9, 1005-1008.

Healy, S. (2009). Pschiatric Drugs Explained, Section 5. Management of anxiety, Elsevier Health Sciences, 4(1), 136137.

Kgosikebatho, K. (2013). Experts pinpoint causes of poor results. Retrieved 19 July, 2017 from: www.thepatriotonsunday.co.bw/experts-pinpoint-causes-of-poor-results.

Liebert, R. M. \& Morris, L. W. (1967). Cognitive and emotional components of test anxiety: A distinction and some initial data. Psychological Reports, 20, 975-978.

McDonald, A. (2001). The prevalence and effects of test anxiety in school children. Edu Psy 21(1), 89-101.

Ministry of Education (2017). Education sector performance report in Ghana. Accra: Ministry of Education.

Omoniyi, T. \& Oluniyi, E. A. (2012). Impact of captioned video instruction on Nigerian hearing impaired students' performance in English Language. The African Symposium: An online journal of the African Educational Research Network, 12(2), 3-10.

Onyesom, M. \& Ashibogwu, N. K. (2013). Towards quality assurance in business education in Nigeria: Constraints and control. Asian Journal of Business Management, 5(3), 306-312.

Polit, D. F., \& Beck, C. T. (2014). Essentials of nursing research: Appraising evidence for nursing practice ( $7^{\text {th }}$ ed.). Philadelphia: Lippincott Williams \& Wilkins.

Putwain, D. W. (2007). Test anxiety in UK schoolchildren: prevalence and demographic patterns. British Journal of Educational Psychology, 77, 579.

Rana, R. A., \& Mahmood, N. (2010).The relationship between test anxiety and academic achievement. Bulletin of Education and Research, 32, 63-74.

Saedi, M., \& Khaliliaqdam, S. (2013). The effect of socio- affective strategies on students' test anxiety across different genders. Theory and Practice in Language Studies, 3(2), 269-274.

Salend, S. J. (2011). Addressing test anxiety. Teaching exceptional children, 44(2), 58-68.

Sansgiry S, \& Sail, K. (2006). Effect of students' perceptions of course load on test anxiety. American Journal of Pharmaceutical Education 70(2), 26-36. 
Segool, N., Carlson, J., Goforth, A., vonderEmbse, N., \& Barterian, J. (2013). Heightened test anxiety among young children: Elementary school students' anxious responses to high-stakes testing. Psychology in the Schools, 50(5), 489-499.

Smith, C. A., \& Ellsworth, P. C. (1987). Patterns of appraisal and emotion related to taking an exam. Journal of Personality and Social Psychology, 52, 475-488.

Steinmayr, R., Crede, J., McElvany, N., \& Wirthwein, L. (2016). Subjective well-being: Test anxiety, academic achievement testing for reciprocal effects. Frontier Psychology, 6, 19-94.

Yousefi, F., Talib,M. A., Mansor, M. B., Juhari, R. B.. \& Redzuan, M. (2010). The relationship between test-anxiety and academic achievement among Iranian adolescents. Asian Social Science, 6(5), 100-105.

Zaheri, F., Shahoei, R., \& Zaheri, H. (2012). Gender differences in test anxiety among students of guidance schools in sanandaj, iran. Wudpecker Journal of Medical Sciences, 1(1), 1-5.

Zeidner, M. (1998). Test anxiety: The state of the art. Plenum Press, New York. 